\title{
Electrochemical Processes for Water Quality Upgradation
}

Vasudevan $\mathbf{S}^{*}$

CSIR, Central Electrochemical Research Institute, Karaikudi-630006, India

\begin{abstract}
Water crisis has become a part of our life. This is not altogether due to shortage of rain fall. Increasing population, growing industrialization, expanding urbanization, agriculture etc. demand more and more water. Coping up with these developments requires various tactics to overcome the water shortage and satisfy the need of all. The main activity in this direction is to decrease the pollution level of discharged effluents and treatment of contaminated water to acceptable quality. In this context, the role of electrochemistry to environmental applications is expanding due to the characteristics of electrochemical processes viz., versatility, energy efficiency, environmental compatibility, cost effectiveness etc. The growth of electrocatalysts and electrochemical engineering in the past two decades has made a total revolution in the electrode and cell design technologies that are particularly important for water and effluent treatment. In this review, brief accounts of a few successful electrochemical technologies are presented.
\end{abstract}

\section{Electrochemical Water Treatment Processes}

Electrochemical technologies for environmental applications can be broadly divided two categories viz., physical (eg. electro-dialysis, electrocoagulation and electro-flotation) and chemical involving direct reaction at the electrode or an indirect reaction with a reagent generated electrolytically.

\section{Electrodialysis (ED)}

Electrodialysis is a membrane based process involving the separation and concentration of electrolytes (dissolved salt concentration) by the electro-migration of the species through ion exchange membranes. Anion and cation exchange membranes are arranged alternatively between two electrodes which enable ions to pass through one type of membrane while the other membrane blocks the passage thus creating a set of "concentrating" cells and "dilution/purification" cells. Cellulose acetate membranes are conventionally used in ED stacks and polysulfone, polyacrylonitrie and polyfluorosulphonic acid type membranes are some of the new membranes presently in use. The water to be purified is circulated through the dilution compartment and the dissolved salts get concentrated in the stream through the concentration compartment.

\section{Electrocoagulation}

Electrocoagulation is the process of destabilising suspended, emulsified, or dissolved contaminants in an aqueous medium by introducing an electric current into the medium. In other words, electrocoagulation is the electrochemical production of destabilisation agents that brings about neutralization of electric charge for removing pollutant. Once charged, the particles bond together like small magnets to form a mass. In its simplest form, an electrocoagulation unit is made up of an electrolytic cell with one anode and one cathode. The conductive metal plates/rods are, commonly known as sacrificial electrodes, made up of the same or different materials are used as the anode and cathode.

\section{Electroflotation}

Electroflotation is a simple process that floats pollutants to the surface of a water body by tiny bubbles of hydrogen and oxygen gases generated from water electrolysis. Therefore, the electrochemical reactions at the cathode and anode are hydrogen evolution and oxygen evolution reactions, respectively. Graphite and lead dioxide are among the most common anode used in electroflotation.

\section{Anodic Oxidation}

Anodic oxidation is a process in which the pollutants can be removed by oxidation. Direct and indirect oxidation can be applied in regard to anodic oxidation processes. In the direct processes the destruction of noxious spices can be accomplished by the electrochemical oxidation at the anode surface. For example in the cyanide removal it is oxidized at the anode at high temp $\left(\sim 80^{\circ} \mathrm{C}\right)$ for several days, there by converting to obtain carbon dioxide and nitrogen. In the indirect method where the generated oxygen or ozone or hypochlorite or free chlorine by electrochemical means can be used as oxidant to destroy the pollutants or sterilize the noxious materials is more advantageous than the direct method, since apart from the complete cyanide destruction, metal ion constituents of the wastes can also be removed. Here cyanide is oxidized to nitrogen and carbon dioxide by electrolyzing the waste alone with steel cathode, the current density being $2-13 \mathrm{~A} / \mathrm{dm}^{2}$. The hypochlorite generated electrolytically oxidizes cyanide to carbon dioxide and nitrogen. Ozone is also used for the destruction of cyanide, which involves two separate chemical steps, oxidation of cyanide to cyanate and further oxidation or hydrolysis of cyanide to nitrogen or ammonia.

\section{Cathodic Reduction}

Cathodic Reduction is a process in which the removal of toxic metal ions presents in the industrial effluents or form drinking water (in lower quantities) can be effectively carried out, to meet the permissible concentration of metal ions in water. The electrochemical process involves in the reduction of metal ions to its elemental or easily removable from. Since the metal ion concentration is very low, the mass transport can be accelerated by different techniques like rotation

*Corresponding author: S. Vasudevan, CSIR - Central Electrochemical Research Institute, Karaikudi-630006, India, Tel: 00-91-4565-241278; Fax: 00-91-4565227779; E-mail: svasudevan65@gmail.com

Received September 20, 2013; Accepted September 20, 2013; Published September 21, 2013

Citation: Vasudevan S (2013) Electrochemical Processes for Water Quality Upgradation. Int J Waste Resources 3: 121. doi: 10.4172/2252-5211.1000e101

Copyright: @ 2013 Vasudevan S. This is an open-access article distributed under the terms of the Creative Commons Attribution License, which permits unrestricted use, distribution, and reproduction in any medium, provided the original author and source are credited. 
Citation: Vasudevan S (2013) Electrochemical Processes for Water Quality Upgradation. Int J Waste Resources 3: e101. doi: 10.4172/22525211.1000 e101

Page 2 of 3

of cathode, forced electrolyte flow, fluidized bed, packed bed etc. One of the applications of this phenomenon is the removal of iron from pickle liquor from steel industries, where the reduction takes place in the form of metal.

\section{Photo Electrochemical Methods}

Photo-electrochemical methods have led to a new and interesting possibility for treatment of pollutants from wastewater. In this case, suspensions of semiconductor particles $\left(\right.$ mostly $^{\mathrm{TiO}}{ }_{2}$ ) can be used to harness the light with production of electrons and holes in the solid, which can destroy pollutants by means of reduction and oxidation, respectively. In this way, water containing organic, inorganic or microbiological pollutants can be effectively treated.

\section{Electrochemical Advanced Oxidation Processes}

Electrochemical Advanced Oxidation Processes is a method where the persistent organic compounds can be removed easily by 'In-situ' generated strong oxidant namely hydroxyl radical $(\bullet \mathrm{OH})$. In this regard, electrochemistry constitutes one of the clean and effective ways to produce ' $I n$-situ' hydroxyl radical $(\bullet \mathrm{OH})$, a highly strong oxidizing agent of organic matter in waters. Due to its very high standard oxidation power $\left(\mathrm{E}^{\circ}\left(\bullet \mathrm{OH} / \mathrm{H}_{2} \mathrm{O}\right)=2.80 \mathrm{~V} / \mathrm{SHE}\right)$, this radical species is able to react non-selectively with organic or organometallic pollutants yielding dehydrogenated or hydroxylated derivatives, which can be in turn completely mineralized, i.e., converted into $\mathrm{CO}_{2}$, water and inorganic ions.

The CSIR-Central Electrochemical Research Institute, Karaikudi, India with its vast experience in the field of electrochemical technologies has developed a number of processes mentioned above.

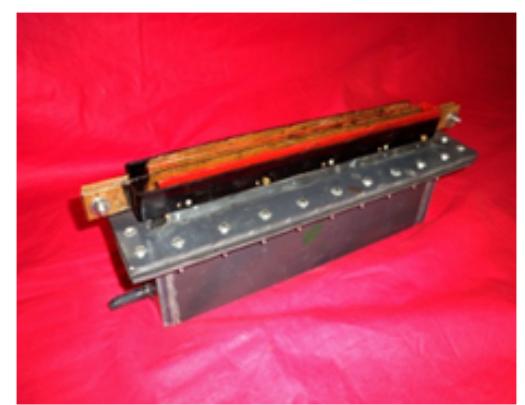

Figure 1: The electrochemical hypochlorite generator of 100 and $500 \mathrm{gm} / \mathrm{hr}$ is already on the market.

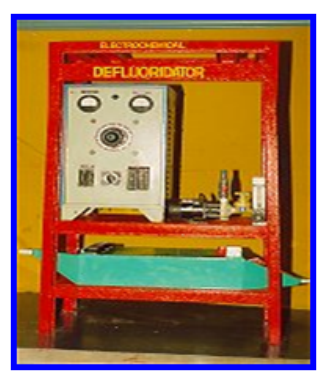

Figure 2: The electrochemical removal of fluoride from drinking water based on electrocoagulation process is already commercialized. The process involves the generation of aluminum hydroxide by the anodic dissolution of aluminum, which adsorbs the fluoride and settles.
The electrochemical hypochlorite generator of 100 and $500 \mathrm{gm} / \mathrm{hr}$ is already on the market (Figure 1). The electrochemical removal of fluoride from drinking water based on electrocoagulation process is already commercialized. The process involves the generation of aluminum hydroxide by the anodic dissolution of aluminum, which adsorbs the fluoride and settles (Figure 2). The electrochemical removal of arsenic from drinking water based on electro coagulation process (Figure 3). Electrochemical ozone generator based on PEM technology has been tested in the laboratory scale and a portable ozone generator (Figure 4). The electrochemical removal of nitrate from drinking water based on reduction cum oxidation process is successfully developed (Figure 5).

Electrochemical technologies offer simple, efficient and cost

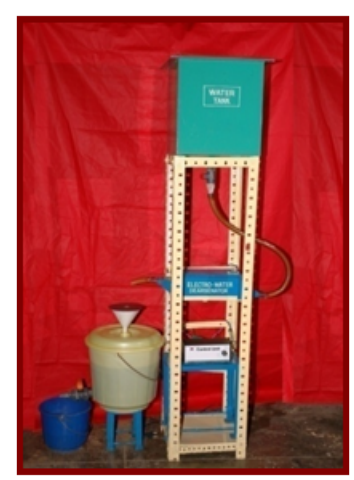

Figure 3: The electrochemical removal of arsenic from drinking water based on electro coagulation process.

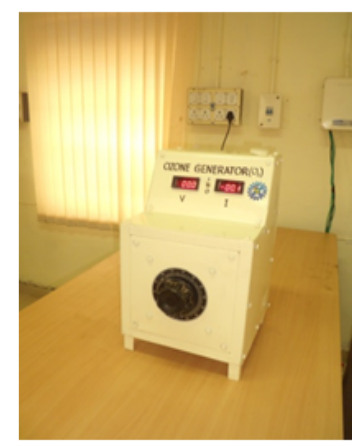

Figure 4: Electrochemical ozone generator based on PEM technology has been tested in the laboratory scale and a portable ozone generator.

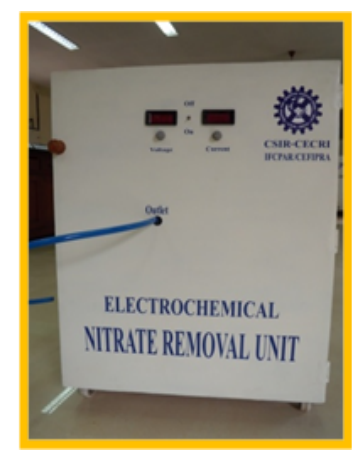

Figure 5: The electrochemical removal of nitrate from drinking water based on reduction cum oxidation process is successfully developed. 
Citation: Vasudevan S (2013) Electrochemical Processes for Water Quality Upgradation. Int J Waste Resources 3: e101. doi: 10.4172/2252$5211.1000 \mathrm{e} 101$

Page 3 of 3

effective solutions to environmental problems and in certain applications superiority over conventional clean up processes have been demonstrated. The superiority is due to the fact that by itself electrochemical methods do not require any external reagents for pollution treatment. Simple user friendly processes can be designed with help of latest advantage in electrode and cell design technologies. 